\title{
Positive Psychological Capital (PsyCap) Meets Multitrait-Multimethod Analysis: Is PsyCap a Robust Predictor of Well-Being and Performance Controlling for Self-Report Bias?
}

\author{
Scott I. Donaldson ${ }^{1} \cdot$ Stewart I. Donaldson ${ }^{2} \cdot$ Lawrence Chan ${ }^{2}$. \\ Kyoung Wan Kang ${ }^{2}$
}

Accepted: 2 November 2021 /Published online: 3 December 2021

(c) The Author(s), under exclusive licence to Springer Nature Switzerland AG 2021

\begin{abstract}
A growing body of evidence suggests positive psychological capital (PsyCap) strongly predicts well-being and performance at work. However, most of this empirical research has used self-report survey designs, increasing the possibility of selfreport and mono-method bias. The current study used a multitrait-multimethod (MTMM) research design and condition-based regression analysis to examine the effect of PsyCap on job well-being and work role performance beyond self-report bias. Findings from 416 full-time employees within 208 coworker pairs showed that self-reported and informant-reported PsyCap were predictive of job well-being and work role performance. However, multitrait-multimethod analyses showed monomethod measures may inflate the strength of association between PsyCap and work outcomes. Implications for future applied positive psychology research controlling for self-report and monomethod bias with multiple data sources are discussed.
\end{abstract}

Keywords Psychological capital · Well-being · Performance, self-report bias · Positive organizational behavior · Positive organizational psychology, MTMM

At the turn of the twenty-first century, Fred Luthans (Luthans, 2002) introduced Positive Psychological Capital (PsyCap) to the management and organizational behavior literature, inspired by Seligman and Csikszentmihalyi's (2000) positive psychology movement. Two decades later and the role of PsyCap on employee wellbeing and performance is well-documented. Several systematic reviews, meta-analyses, and PsyCap intervention studies demonstrate a relationship between PsyCap

Scott I. Donaldson

scottdon@usc.edu

1 USC Keck School of Medicine, University of Southern California, Los Angeles, CA, USA

2 Claremont Evaluation Center, Claremont Graduate University, Claremont, CA, USA 
and desirable attitudes, behaviors, performance, and well-being (Avey et al., 2011; Dawkins et al., 2013; Donaldson et al., 2019; Newman et al., 2014). The impact of PsyCap on workplace well-being and performance has even been demonstrated across international contexts, including countries such as Australia, France, Italy, and South Africa to name a few (Donaldson et al., 2020a). Still, there is an open debate on how self-report and monomethod bias from survey measures may have influenced previous research findings on PsyCap (Luthans \& Youssef-Morgan, 2017). The current study shed light on this major concern for organizational behavior researchers and practitioners working to improve PsyCap in the workplace.

Luthans (2002) defined PsyCap as a "positively oriented human resource strength and psychological capacity that can be measured, developed, and effectively managed for performance improvement in today's workplace" (p. 59). This evidence-based and validated construct has been cited more than 4300 times since 2007 (cf. Luthans et al., 2007). Positive psychological capital is measured by four theory-driven subdimensions sometimes described by the acronym HERO (Luthans \& Youssef-Morgan, 2017):

\begin{tabular}{lll}
\hline Hope & - & goal-directed agency and planning (Snyder et al., 1996) \\
Efficacy & - & ability to execute tasks (Parker, 1998) \\
Resilience & - & overcome adversity and bounce back (Wagnild \& Young, 1993) \\
Optimism & - & positive outlook and explanatory style (Scheier \& Carver, 1985) \\
\hline
\end{tabular}

The relationship between PsyCap and work outcomes is of critical importance to practitioners, human resource managers, leaders, and organizational scholars interested in a positive approach to work. Avey et al. (2011) meta-analyzed PsyCap in the workplace using 51 samples representing more than 12,000 employees. Avey and colleagues found that PsyCap was a significant predictor of work performance, well-being, and negatively related to undesirable work outcomes (e.g., deviance, turnover intentions). Donaldson et al.'s (2019) meta-analysis of positive psychology interventions at work found a similar result for the impact of PsyCap interventions on work outcomes. For instance, PsyCap interventions were particularly effective at reducing undesirable work outcomes (e.g., turnover intentions). Another systematic review and synthesis of PsyCap found a relationship between PsyCap and individual, team, and organizational work outcomes, including absenteeism, team performance, and financial performance (Newman et al., 2014). The impact of PsyCap on well-being and performance has even been demonstrated in international contexts. Donaldson et al. (2020a, b) found that PsyCap was a strong predictor of overall work performance and well-being across 15 nations, some of which included Australia, France, Italy, and South Africa to name a few. Moreover, Adil and Kamal (2018) found that PsyCap was a significant predictor of job-related affective well-being (JAWS) in a sample of 500 Pakistani university teachers.

The most used measure in studies of PsyCap is the psychological capital questionnaire (PCQ-24), including a short version (PCQ-12) that measures each of PsyCap's subdimensions with 2-4 survey items (i.e., 4 items for hope, 3 for 
self-efficacy and resilience, and 2 for optimism; Luthans et al., 2007). Luthans et al. (2007) validated the PCQ using four samples and found Cronbach alphas between .66 and .85 for each subscale and alphas above .88 for the overall scale. Dawkins et al. (2013) performed a critical analysis and psychometric review of the PCQ and suggested future research include methodological diversity to further explore convergent and discriminant validity. In another research synthesis of PsyCap, Newman et al. (2014) reported that the majority of studies on PsyCap suffer from self-report bias and that alternative measures, such as other-rated measures of PsyCap from partners and supervisors should be considered to control for common method variance.

Multitrait-multimethod (MTMM) research designs use at least two sources of information to measure the constructs of interest. For example, both self-reports and co-worker informant reports of PsyCap, well-being, and performance were used in this study. This allowed us to assess the convergent validity of our measurement approach, and to determine how much our measures were inflated by self-report and mono-methods bias (Campbell \& Fiske, 1959; Meade et al., 2007; Podsakoff et al., 2003). Miner and Hulin (2006) suggest workplace studies that rely on selfreport measures are prone to social desirability bias. Donaldson and Grant-Vallone (2002) provide four factors that may motivate bias in workplace research: sensitivity of the construct, true state of affairs, dispositional characteristics, and situational characteristics (see Fig. 1). These motivational biases make it difficult for organizational researchers to understand the true relationship between self-reported PsyCap and work performance. To combat possible self-enhancement effects that

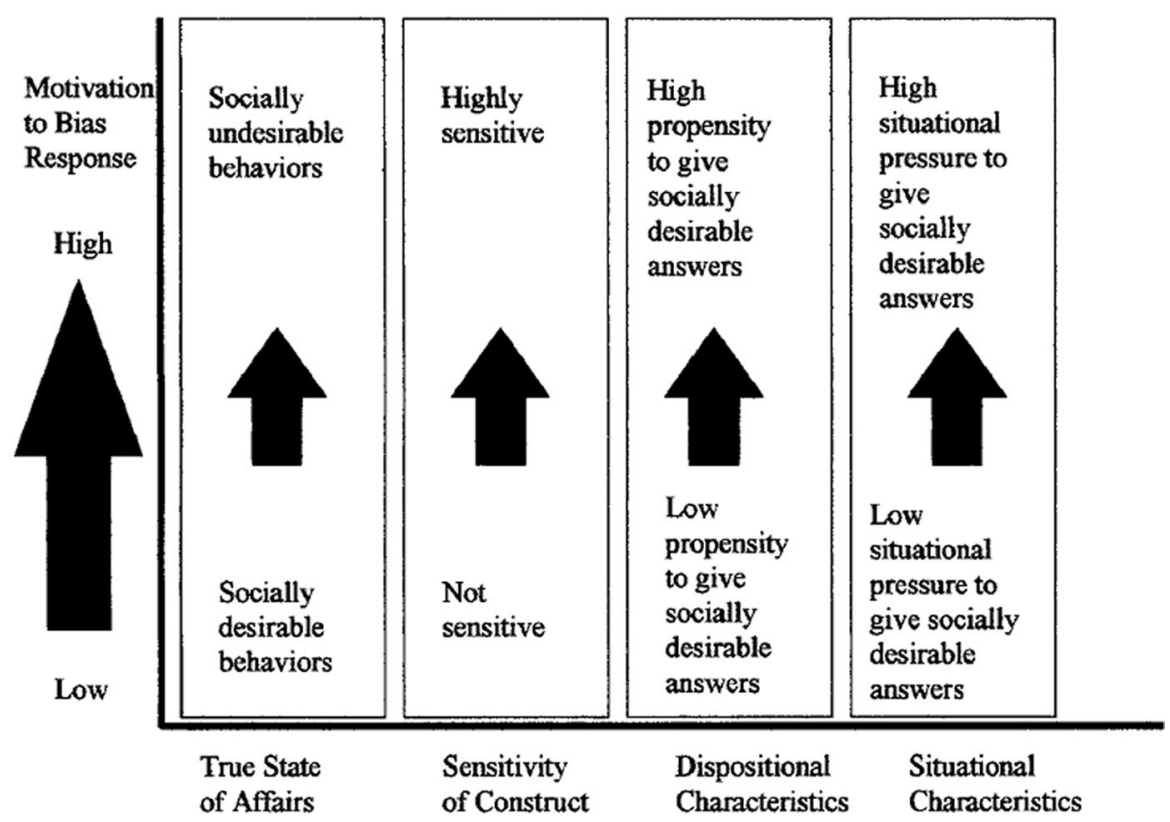

Fig. 1 Four Factors that Influence Self-Report Bias (Donaldson \& Grant-Vallone, 2002) 
may be influenced by social desirability bias, Humberg et al. (2018) developed a novel approach to allow researchers to detect self-enhancement in their data. This conditioned-based regression analysis mathematically disentangles the relationship between self-reports, informant-reports, and how the discrepancy between selfreports and informant-reports impacts the outcome of interest. Recently, Donaldson, Heshmati, et al. (2020b) examined two positive psychology constructs (PERMA and subjective well-being) using an MTMM research design, and found support for inflated parameter estimates between self-reported and informant-reported well-being.

\section{Current Study}

The purpose of the current study was to apply the MTMM research design implemented in Donaldson et al. (2020a, b) to investigate PsyCap, job-related affective well-being (JAWS), and work role performance. This is one of the first empirical studies to examine PsyCap using employee self-reports and employee informantreports simultaneously. The following hypotheses were tested:

1. The relationship between the subdimensions of PsyCap (HERO), JAWS, and work role performance will be statistically significant for self-reports and informantreports.

2. A multitrait-multimethod matrix of PsyCap, JAWS, and work role performance will demonstrate the desideratum criteria of convergent and discriminant validity proposed by Campbell and Fiske (1959). That is:

a) Convergence correlations between self-reported and informant-reported PsyCap, JAWS, and work role performance should be statistically significant.

b) Values in the validity diagonals should be higher than the values in theheterotraitheteromethod blocks.

c) Values in the validity diagonals should be higher than the values in the heterotraitmonomethod blocks.

d) The relationship between PsyCap, JAWS, and work role performance should show the same pattern across all of the heterotrait and monomethod triangles.

3a PsyCap will be associated with self-enhancement, meaning higher values in the discrepancy between self-reports and informant-reports of PsyCap will predict higher values in JAWS and work role performance (i.e., calculated as the average score between self- and informant-reports).

3b PsyCap will be associated with positive self-reports, meaning higher values in self-reports will be predictive of higher values in JAWS and work role performance. 


\section{Method}

The data reported in this manuscript were collected as part of a larger MTMM study focused on understanding the effects of self-report and mono-method bias in positive organizational behavior research. Donaldson et al. (2020a, b) published a paper on PERMA and subjective well-being which appeared in the Journal of Positive Psychology, and have another manuscript in press focused on the relationship between PERMA+4 and work role performance. However, the hypotheses and constructs analyzed in this paper are original and have not been published or presented prior to this submission.

\subsection{Participants}

Participants consisted of 416 full-time employees, including 208 coworker pairs. The average age was $40(S D=12.5)$. Six participants did not report their age. Most employees reported their gender identity as female $(56 \%, n=231)$ or male $(43 \%$, $n=181)$. Three employees did not report their gender. The majority of participants were White $(63 \%, n=260)$, Black $(11 \%, n=46)$, and Asian $(10 \%, n=41)$. In terms of educational attainment, Bachelor's degree $(39 \%, n=158)$, Master degree $(26 \%$, $n=105)$, Associate degree $(20 \%, n=83)$ were the most common. Nine participants did not report their highest degree. Represented work industries included Food and Beverage (19\%, $n=78)$, Banking $(13 \%, n=54)$, and Media \& Entertainment $(13 \%$, $n=55)$. Seven participants did not report their work industry. Approximately $70 \%$ of participants reported an annual income between 25 and 99 thousand dollars. Two participants did not report their income. Table 1 presents participants demographic characteristics.

\subsection{Procedure}

Qualtrics panels recruited a sample of full-time employees in the U.S. Participants received an email with survey instructions and were incentivized to complete the survey with a gift card. In the first part, incumbents completed the Psychological Capital Questionnaire (PCQ), JAWS, and the organizational-level items on the Work Role Performance Scale (Griffin et al., 2007; Luthans et al., 2007; Van Katwyk et al., 2000). The second part of the study included a transition between the incumbent and their closest coworker. The instructions read, "For the next stage of the survey, we ask that you please answer the questions about your closest coworker. Thank you for your participation." The close coworker then completed the items about their colleague. Demographic characteristics were included at the end of survey, such as gender, ethnicity, education, and income. 
Table 1 Participant demographic Characteristics

\begin{tabular}{|c|c|c|}
\hline Demographic variable & $n$ & Mean (SD) or \% \\
\hline Age & 410 & $40(12.5)$ \\
\hline \multicolumn{3}{|l|}{ Gender } \\
\hline Female & 231 & $56 \%$ \\
\hline Male & 181 & $44 \%$ \\
\hline Other & 1 & $<1 \%$ \\
\hline \multicolumn{3}{|l|}{ Race/Ethnicity } \\
\hline NH-White & 260 & $63 \%$ \\
\hline NH-NHOPI & 2 & $<1 \%$ \\
\hline NH-Multiple race & 48 & $12 \%$ \\
\hline NH-Black & 46 & $11 \%$ \\
\hline NH-Asian & 41 & $10 \%$ \\
\hline NH-AI/AN & 4 & $<1 \%$ \\
\hline Hispanic & 15 & $4 \%$ \\
\hline \multicolumn{3}{|l|}{ Degree } \\
\hline Associate & 83 & $20 \%$ \\
\hline Bachelors & 158 & $39 \%$ \\
\hline Masters & 105 & $26 \%$ \\
\hline Doctorate & 32 & $8 \%$ \\
\hline Other & 29 & $7 \%$ \\
\hline \multicolumn{3}{|l|}{ Income } \\
\hline Less than $25 \mathrm{k}$ & 28 & $7 \%$ \\
\hline $25-49 \mathrm{k}$ & 102 & $25 \%$ \\
\hline $50-74 \mathrm{k}$ & 96 & $23 \%$ \\
\hline $75-99 \mathrm{k}$ & 90 & $22 \%$ \\
\hline $100-150 \mathrm{k}$ & 80 & $19 \%$ \\
\hline $150 \mathrm{k}+$ & 18 & $4 \%$ \\
\hline \multicolumn{3}{|l|}{ Industry } \\
\hline Banking \& Financial Services & 54 & $13 \%$ \\
\hline Education & 12 & $3 \%$ \\
\hline Food \& Beverage & 78 & $19 \%$ \\
\hline Government & 50 & $12 \%$ \\
\hline Healthcare & 19 & $5 \%$ \\
\hline Manufacturing & 40 & $10 \%$ \\
\hline Media \& Entertainment & 55 & $13 \%$ \\
\hline Retail, Wholesale, \& Distribution & 39 & $10 \%$ \\
\hline Software \& IT Services & 7 & $2 \%$ \\
\hline Non-Profit & 27 & $6 \%$ \\
\hline Other & 28 & $7 \%$ \\
\hline
\end{tabular}

Other $=\mathrm{I}$ identify my gender in another way or I prefer not to answer; $\mathrm{NH}=$ Non-Hispanic, $\mathrm{AI} / \mathrm{AN}=$ American Indian or Alaska Native, NHOPI $=$ Native Hawaiian and Other Pacific Islander 


\section{Measures}

Psychological Capital Questionnaire The PCQ measures the four dimensions of PsyCap - hope, self-efficacy, resilience, and optimism. Two items on each construct were adapted for the current study. Example items include "I feel confident representing my work in a meeting with management," and "If I should find myself in a jam at work, I could think of many ways to get out of it." These items were modified for the informant-reports. For example, "My colleague feels confident representing his/her work in a meeting with management." Luthans et al. (2007) found support for the reliability and validity of the PCQ, and found predictive validity with job performance and well-being.

Job-Related Affective Well-Being The 10-item short version of the JAWS scale was used to measure well-being (Van Katwyk et al., 2000). The JAWS scale is comprised of four subdimensions: high pleasurable-high arousal emotions (HPHA; e.g., energetic, excited), high pleasurable-low arousal emotions (HPLA; e.g., at-ease, calm), low pleasurable-high arousal emotions (LPHA; e.g., angry, anxious), and low pleasurable-low arousal (LPLA; e.g., bored, depressed) emotions. A wealth of research supports the validity of the JAWS scale in various populations (Van Katwyk et al., 2000). Responses are measured on a five-point Likert-type scale from 1 (Never) to 5 (Extremely Often). Example items include "My job made me feel angry," and "My job made me feel fatigued." These items were modified for informant-reports.

Work Role Performance Organizational proactivity, organizational proficiency, and organizational adaptivity were measured using the work role performance measure developed by Griffin et al. (2007). Griffin and colleagues reported a ninefactor structure (i.e., each dimension at the individual, team, and organizational level) fit best with excellent internal consistencies (alpha ranging from 83 to 93). Using three items on each construct, participants reported their organizational proficiency, organizational proactivity, and organizational adaptivity in the workplace on a 7-point Likert-type scale from 1 (Strongly Disagree) to 7 (Strongly Agree). An example item includes "I cope with changes in the way the organization operates." These items were modified for informant-reports.

\subsection{Analytic Strategy}

All analyses were conducted in $\mathrm{R}$ (version 3.6.1, $\mathrm{R}$ Foundation for Statistical Computing, 2019) using the psych (Revelle, 2019), Hmisc (Harrell, 2019), QuantPsyc (Fletcher, 2010), and lavaan (Rosseel, 2012) packages. Pearson's linear correlation coefficients and Cohen's $D$ were computed between PsyCap, JAWS, and work role performance. For the conditioned-regression analysis, coefficients and their standard errors were computed from the linear regression eq. $\mathrm{Z}=c_{0}+c_{1} S+c_{2} R+\varepsilon . \mathrm{Z}$ corresponds to JAWS and work role performance, $\mathrm{S}$ and $\mathrm{R}$ reflect self-reported and informant-reported PsyCap, respectively, $c$ refers to 
their parameters, and $e$ represents measurement error. The second part of the computation is the parameter for self-enhancement of $a b s:\left|c_{1}-c_{2}\right|-\left|c_{1}+c_{2}\right|$ and the standard error of those terms calculated using lavaan in R (Rosseel, 2012). The more the parameter $a b s>0$, the higher the self-enhancement effect is in the data. A significant $c_{1}$ parameter provides support for the positive self-view hypothesis, which states that higher self-reports are related to higher values in an outcome of interest. A significant $c_{2}$ parameter suggests that controlling for selfreports, informant-reports are predictive of an outcome of interest. Example R code and open science framework materials were used to compute the conditionbased regression analysis (see https://osf.io/e8p5r/).

\section{Results}

\subsection{Initial Data Analysis}

Exploratory data analyses showed that PsyCap, JAWS, and organizational adaptivity, proactivity, and proficiency were normally distributed with no significant skewness or kurtosis statistics. The initial sample consisted of 221 coworker pairs with 100\% completed self-reports on PsyCap, JAWS, and work role performance. Thirteen pairs had incomplete informant-reports on either measure of PsyCap, JAWS, or work role performance and were dropped from further analyses. This resulted in an analytic sample of 416 employees nested in 208 coworker pairs.

\subsection{Convergence between PsyCap, JAWS, and Work Role Performance}

The convergence correlations between self-reported and informant-reported PsyCap, JAWS, and work role performance were significant and strong, ranging from $r=.58$ to .82 . Table 2 presents descriptive statistics and convergence $(r)$ between self-reported and informant-reported PsyCap, JAWS, and work role performance. Table 2 also shows mean differences between self-reports and informant-reports on study variables using Cohens $D$. All mean differences were small.

Table 3 shows convergence correlations between self-reported hope, self-efficacy, resilience, optimism, and self- and informant-reported JAWS and work role performance. All correlations in Table 3 were strong, ranging from $r=.58$ to .81 . Selfreported correlations between hope, self-efficacy, resilience, and optimism and work outcomes were systematically higher than correlations between self-reported hope, self-efficacy, resilience, and optimism for informant-reported work outcomes. These findings provide support for Hypothesis 1.

\subsection{Multitrait-Multimethod Matrix}

Hypothesis $2 a$ stated that convergence correlations should be statistically significant and warrant future attention. Table 4 shows strong positive correlations (all 
Table 2 Means, SDs, Zero-Order Correlations, and Mean Differences between Self-Reported and Informant-Reported Psychological Capital, JAWS, and Work Role Performance

\begin{tabular}{llllllll}
\hline & \multicolumn{3}{l}{ Self-reports } & \multicolumn{2}{l}{$\begin{array}{l}\text { Informant- } \\
\text { reports }\end{array}$} & Convergence $(\mathrm{r})$ & Cohens $(D)$ \\
\cline { 2 - 3 } Variables & $M$ & $S D$ & & $M$ & $S D$ & & \\
\hline Psychological Capital & 5.16 & 1.14 & 5.06 & 1.17 & $.75^{* *}$ & $.09[-0.04, .23]$ \\
Hope & 5.15 & 1.21 & 5.10 & 1.24 & $.68^{* *}$ & $.05[-0.09, .18]$ \\
Self-Efficacy & 5.18 & 1.34 & 5.10 & 1.31 & $.58^{* *}$ & $.06[-0.07, .20]$ \\
Resilience & 5.23 & 1.22 & 4.99 & 1.32 & $.59^{* *}$ & $.18[0.05, .32]$ \\
Optimism & 5.10 & 1.25 & 5.04 & 1.22 & $.70^{* *}$ & $.05[-0.09, .18]$ \\
JAWS & 3.38 & 0.95 & 3.38 & 0.93 & $.82^{* *}$ & $0.0[-0.14, .14]$ \\
Work Role Performance & & & & & & $.15[.01, .28]$ \\
Organizational adaptivity & 5.25 & 1.22 & 5.06 & 1.22 & $.71^{* *}$ & $.11[-0.02, .25]$ \\
Organizational proactivity & 5.18 & 1.22 & 5.07 & 1.25 & $.68^{* *}$ & $.10[-0.04, .24]$ \\
Organizational proficiency & 5.17 & 1.25 & 5.04 & 1.24 & $.74^{* *}$ & \\
\hline
\end{tabular}

Convergence indicates Pearson correlation coefficients between self-reports and informant-reports for each of the study variables; $* *=p<.01 ; N=416$

correlations $>.68$ ) for PsyCap, JAWS, and work role performance. Thus, the significant validity diagonals provide support for Hypothesis $2 a$. Hypothesis $2 b$ suggested the values in the validity diagonals should be higher than the values in its column and row heterotrait-heteromethod triangles. This evaluation criterion was supported for PsyCap, JAWS, organizational adaptivity, organizational proactivity, and organizational proficiency, but not for the relationship between PsyCap and organizational proficiency $(r=.74)$.

Hypothesis $2 c$ stated that the values in the validity diagonals should be higher than the values in the heterotrait-monomethod blocks. As shown in Table 4, Hypothesis $2 c$ was only supported for JAWS. The validity diagonal for PsyCap, organizational adaptivity, organizational proactivity, and organizational proficiency were unanimously smaller than the heterotrait-monomethod triangles.

Table 3 Correlation Coefficients of Self-Reported Psychological Capital Subdimensions with SelfReported and Informant-Reported JAWS and Work Role Performance

\begin{tabular}{lclllllll}
\hline & Hope & & \multicolumn{2}{c}{ Self-Efficacy } & \multicolumn{2}{l}{ Resilience } & \multicolumn{2}{l}{ Optimism } \\
\hline Variables & Self & Inform & Self & Inform & Self & Inform & Self & Inform \\
JAWS & .68 & .59 & .64 & .54 & .67 & .60 & .72 & .62 \\
Organizational adaptivity & .81 & .69 & .71 & .60 & .76 & .68 & .79 & .67 \\
Organizational proactivity & .76 & .68 & .67 & .58 & .70 & .66 & .74 & .68 \\
Organizational proficiency & .76 & .70 & .71 & .61 & .70 & .67 & .78 & .70 \\
\hline
\end{tabular}

Convergence indicates Pearson correlation coefficients between self-reports and informant-reports for each of the study variables; JAWS = job-related affective well-being; Self = self-reports; Inform = informant-reports; All correlation coefficients were significant at $\mathrm{p}<.01 ; N=416$ 
Table 4 A Multitrait-Multimethod Matrix of Psychological Capital, JAWS, Work Role Performance $(N=416)$.

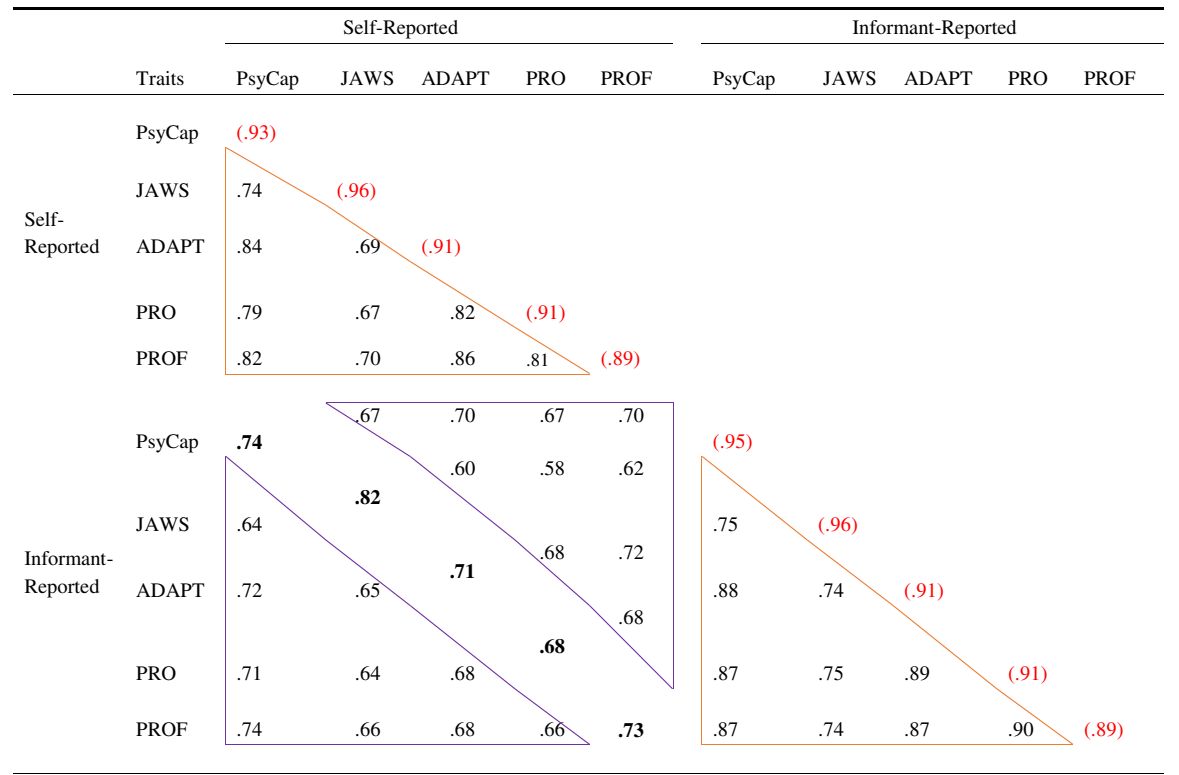

Note . Reliability diagonals = monotrait-monomethod Cronbach's alpha values in red; Monomethod block $=$ orange heterotraitmonomethod triangles; Heteromethod block = purple heterotrait-heteromethod purple; Validity diagonals = monotrait-heteromethod values in bold PsyCap = psychological capital ADAPT $=$ organizational adaptivity $;$ PRO = organizational proactivity; $\mathrm{PROF}=$ organizational proficiency; All correlation coefficients were significant at $\mathrm{p}<.01$.

Finally, Hypothesis $2 d$ tested the pattern of trait interrelationships shown in both the monomethod and heteromethod blocks. The interrelationships in the monomethod blocks compared to the heteroblocks were comparable. Thus, these findings provide support for Hypothesis $2 d$.

\subsection{Effects of Self-Enhancement and Positive Self-Reports of PsyCap on JAWS and Work Role Performance}

Hypothesis $3 a$ suggested PsyCap scores will be self-enhanced, meaning larger differences would exist between self-reported and informant-reported PsyCap relative to JAWS and work role performance. As demonstrated in Table 5, and in concordance

Table 5 Self-Reported and Informant-Reported PsyCap Predicting Averaged SelfReported and InformantReported JAWS and Work Role Performance

\begin{tabular}{llllll}
\hline Work Outcomes & $c_{1}$ & $c_{2}$ & $c_{1}+c_{2}$ & $c_{1}-c_{2}$ & $a b s$ \\
\hline JAWS & .31 & .34 & .65 & -.03 & -.62 \\
Organizational adaptivity & .47 & .47 & .94 & 0.0 & -.95 \\
Organizational proactivity & .44 & .48 & .92 & -.04 & -.89 \\
Organizational proficiency & .44 & .51 & .95 & -.07 & -.89 \\
\hline
\end{tabular}

All $c$ parameters are significant at $p<.05$; According to the CRA approach, an effect of self-enhancement exists if abs: $|c 1-c 2|-|c 1+c 2|$ is significantly positive; $\mathrm{N}=416$ 
with the self-enhancement theorem, $a b s$ was not significant for JAWS and work role performance. Thus, Hypothesis $3 a$ was not supported. However, $c_{1}$ and $c_{2}$ were $>0$ providing support for Hypothesis $3 b$. Thus, increases in self-reported PsyCap were associated with increases in averaged JAWS and work role performance, even if true PsyCap scores varied. Likewise, controlling for self-reports, there was a positive relationship between informant-reported PsyCap and averaged JAWS and work role performance. While there was no significant self-enhancement effect, the $c_{1^{-}}$ $c_{2}$ parameter showed that increases in self-enhancement were associated with lower JAWS and work role performance.

\section{Discussion}

This study examined PsyCap beyond self-report bias using an MTMM research design, including a conditioned-based regression analysis to examine self-enhancement from self-reported data. Several theoretical and practical implications emerged: a) strong positive correlations were observed between PsyCap's subdimensions (HERO), JAWS, and work role performance with a small decrease observed between self-reported and informant-reported work outcomes, b) monomethod correlations between PsyCap, JAWS, and work role performance were higher than heteromethod correlations, and c) there was no self-enhancement effect found between PsyCap, JAWS, and work role performance. However, self-reported and informant-reported PsyCap were significantly associated with JAWS and work role performance. All together, these findings suggest that PsyCap is a strong predictor of employee well-being and performance, and future research should consider multiple measures to obtain the most accurate parameter estimates when interpreting PsyCap's impact on work outcomes.

As displayed in Table 3, each subdimension of PsyCap was strongly correlated with JAWS and work role performance, providing support for Hypothesis 1. When examining the relationship between self-reported PsyCap and informant-reported JAWS and work role performance, the correlation coefficients dropped between .03-.12 for each work outcome, respectively. Dawkins et al. (2013) suggested the relationship between each component of PsyCap and work outcomes should be calculated in addition to an overall PsyCap score. We found convergent validity between HERO and work outcomes, controlling for informant-reports. Future research would benefit from several types of informant-reports in addition to close colleagues, such as supervisors, clients, and subordinates.

Convergent and discriminant validity of PsyCap, JAWS, and work role performance was examined using an MTMM correlation matrix (Campbell \& Fiske, 1959). Internal consistency for all study variables were in the excellent range (Cronbach, 1951). However, the high alpha values $<.90$ may suggest that items on the subscales were redundant (Tavakol \& Dennick, 2011). Table 4 shows that the convergence correlations (i.e., self-reported and informant-reported correlations for each study variable) ranged from .68 to .82 with the adjacent heteromethod triangles being smaller than the convergence correlations. This demonstrates support for Hypothesis $2 a$ and Hypothesis $2 b$. However, a comparison of the convergence correlations and the monomethod triangles shows higher correlations between different 
traits using the same method. This suggests that common method variance may have inflated the correlation coefficients. Newman et al. (2014) warned that common method variance influenced PsyCap and work outcomes in prior meta-analytic research. Interestingly, the convergence correlation for JAWS was higher than monomethod and heteromethod triangles with different traits. A review of studies using JAWS demonstrates reliable and valid measurement across several populations, including primary health care physicians, office workers, and bus drivers to name a few (Machin \& Hoare, 2008; Uncu et al., 2007; Wilkerson et al., 2008). As a result, we did not find support for PsyCap in Hypothesis 2c. Finally, Hypothesis $2 d$ was supported with strong positive relationships between PsyCap, JAWS, and work role performance for monomethod and heteromethod triangles.

Humberg et al. (2018) created a regression analysis that separates the effects of self-enhancement from the effects of positive of self-view. For example, the approach examines the discrepancy between self-reports and informant-reports on work outcomes in addition to the role of self-reports and informant-reports alone. In the current study, self-reported PsyCap was a significant predictor of JAWS and work role performance, providing support for Hypothesis $3 b$. We found no selfenhancement effect of PsyCap in our data. Still, Donaldson and Donaldson (in press) found that more than half of employees agreed that their self-reports may be inaccurate and that they had some concern their answers could get back to their supervisor. As shown in Table 5, controlling for self-reports, informant-reports were predictive of work outcomes. Likewise, controlling for informant-reports, self-reports were predictive of work outcomes. Future studies will need to explore the role of selfenhancement in more validation samples.

Furthermore, Fox et al. (2007) recognize methodological issues may exist within informant-reported data. For example, Horn errors may occur in informant-reports where a rater gives a higher or lower assessment based on a global judgment of their coworker. Donaldson and Grant-Vallone (2002) discussed using self-reported and informant-reported data as a yardstick for the confidence interval between the true score. This recommendation was used to estimate the reality criterion in the current regression analysis. Future research on PsyCap would benefit from using multiple data sources to explore the role of self-report and monomethod bias on well-being and performance.

\section{Limitations and Future Directions}

While this study examined PsyCap's effect on well-being and performance beyond self-report methodology, several limitations deserve further attention. First, we asked employees to recruit their closest coworker. It is possible that employees chose coworkers who had the highest propensity of giving desirable feedback. Fox et al. (2007) suggests coworkers may fear retribution for reporting a fellow coworker's job performance. Second, the data collected was cross-sectional. Future research using MTMM designs would benefit from test-retest reliability, longitudinal data, and using reliable scale measures with modest Cronbach's alpha values to avoid redundant items. Finally, because self-report and informant-report instruments 
are vulnerable to inflated or deflated ratings, objective or archival data like absenteeism would further help us understand the relationship between PsyCap and an objective reality criterion.

\section{Conclusion}

The current study found support for the relationship between PsyCap, job-related well-being, and work role performance using multitrait-multimethod analyses. While PsyCap was a significant predictor of work outcomes, inflated correlations due to monomethod bias may overestimate the effect of PsyCap on work outcomes. More research is needed to investigate the role of self-report and monomethod bias on PsyCap, and explore alternative statistical and design control methods. Finally, we are hopeful that these research findings will spur methodological developments to advance the measurement of this seminal construct in the area of positive organizational behavior.

Acknowledgements The authors would like to sincerely thank colleague Mashi Rahmani, Ph.D. for his support of this project, and for his continuous financial support of our flourishing and social justice research program.

\section{Declarations}

Conflict of Interest The authors declare that they have no conflict of interest.

Ethical Approval This article does not contain any studies with human participants or animals performed by any of the authors.

\section{References}

Adil, A., \& Kamal, A. (2018). Impact of perceived authentic leadership and psychological capital on burnout: Mediating role of psychological ownership. Psychological Studies, 63(3), 243-252.

Avey, J. B., Reichard, R. J., Luthans, F., \& Mhatre, K. H. (2011). Meta-analysis of the impact of positive psychological capital on employee attitudes, behaviors, and performance. Human Resource Development Quarterly, 22(2), 127-152.

Bolier, L., Haverman, M., Westerhof, G. J., Riper, H., Smit, H. F. E., \& Bohlmeijer, E. (2013). Positive psychology interventions: A meta-analysis of randomized controlled studies. BMC Public Health, 13.

Cameron, K. S., Dutton, J. E., \& Quinn, R. E. (2003). Positive organizational scholarship: Foundations of a new discipline (1st ed.). Berrett-Koehler.

Cameron, K. S., \& Spreitzer, G. M. (Eds.). (2012). Oxford library of psychology. Oxford University Press.

Campbell, D. T., \& Fiske, D. W. (1959). Convergent and discriminant validation by the multitrait-multimethod matrix. Psychological Bulletin, 56(2), 81-105.

Cronbach, L. J. (1951). Coefficient alpha and the internal structure of tests. Psychometrika, 16, $297-334$.

Dawkins, S., Martin, A., Scott, J., \& Sanderson, K. (2013). Building on the positives: A psychometric review and critical analysis of the construct of psychological capital. Journal of Occupational and Organizational Psychology, 86(3), 348-370.

DeSimone, J. A., Harms, P. D., \& DeSimone, A. J. (2015). Best practice recommendations for data screening. Journal of Organizational Behavior, 36(2), 171-181. 
Donaldson, S. I., Chan, L. B., Villalobos, J., \& Chen, C. L. (2020a). The generalizability of HERO across 15 nations: Positive psychological capital (psycap) beyond the us and other weird countries. International Journal of Environmental Research and Public Health, 17(24).

Donaldson, S. I., Chen, C., \& Donaldson, S. I. (2021). Designing positive organizational psychology interventions. In S. I. Donaldson \& C. Chen (Eds.), Positive organizational psychology interventions: Design and evaluation. Wiley.

Donaldson, S. I., Donaldson, S. I., \& Ko I. (2020). Advances in the science of positive work and organizations. In S. I. Donaldson, M. Csikszentmihalyi, \& J. Nakamura ( $2^{\text {nd }}$ ed.), Positive psychological science: Improving everyday life, health and well-being, work, education, and society. New York, NY: Routledge Academic.

Donaldson, S. I., \& Grant-Vallone, E. J. (2002). Understanding self-report bias in organizational behavior research. Journal of Business and Psychology, 17(2), 245-260.

Donaldson, S. I., Heshmati, S., Lee, J. Y., \& Donaldson, S. I. (2020b). Examining building blocks of well-being beyond PERMA and self-report bias. The Journal of Positive Psychology, 1-8.

Donaldson, S. I., Lee, J. Y., \& Donaldson, S. I. (2019). Evaluating positive psychology interventions at work: A systematic review and meta-analysis. International Journal of Applied Positive Psychology, 4, 113-134.

Fletcher, T. D. (2010). Package 'QuantPsyc'. https://cran.r-project.org/web/packages/QuantPsyc/Quant Psyc.pdf/

Fox, S., Spector, P. E., Goh, A., \& Bruursema, K. (2007). Does your coworker know what you're doing? Convergence of self- and peer-reports of counterproductive work behavior. International Journal of Stress Management, 14(1), 41-60.

Griffin, M. A., Neal, A., \& Parker, S. K. (2007). A new model of work role performance: Positive behavior in uncertain and interdependent contexts. The Academy of Management Journal, 50(2), 327-347.

Harrell, F. (2019). Hmisc: Harrell miscellaneous. R package version, 4-2-0. Retrieved from https://cran.rproject.org/web/packages/Hmisc/Hmisc.pdf/

Huang, J. L., Curran, P. G., Keeney, J., Poposki, E. M., \& DeShon, R. P. (2012). Detecting and deterring insufficient effort responding to surveys. Journal of Business and Psychology, 27(1), 99-114.

Humberg, S., Dufner, M., Schönbrodt, F. D., Geukes, K., Hutteman, R., van Zalk, M. H. W., Denissen, J. J. A., Nestler, S., \& Back, M. D. (2018). Enhanced versus simply positive: A new condition-based regression analysis to disentangle effects of self-enhancement from effects of positivity of self-view. Journal of Personality and Social Psychology, 114(2), 303-322.

Luthans, F. (2002). The need for and meaning of positive organizational behavior. Journal of Organizational Behavior, 23(6), 695-706.

Luthans, F., Avolio, B. J., Avey, J. B., \& Norman, S. M. (2007). Positive psychological capital: Measurement and relationship with performance and satisfaction. Personnel Psychology, 60(3), 541-572.

Luthans, F., \& Youssef-Morgan, C. M. (2017). Psychological capital: An evidence-based positive approach. Annual Review of Organizational Psychology and Organizational Behavior, 4, 339-366.

Machin, M. A., \& Hoare, P. N. (2008). The role of workload and driver coping styles in predicting bus drivers' need for recovery, positive and negative affect, and physical symptoms. Anxiety, Stress \& Coping: An International Journal, 21(4), 359-375.

Meade, A. W., Watson, A. M., \& Kroustalis, C. M. (2007). Assessing common methods bias in organizational research. Paper presented at the 22nd Annual Meeting of the Society for Industrial and Organizational Psychology, New York.

Miner, A. G., \& Hulin, C. L. (2006). Multimethods in industrial and organizational psychology: Expanding "methods" to include longitudinal designs. In M. Eid \& E. Diener (Eds.), Multimethod measurement in psychology (pp. 429-439). American Psychological Association.

Newman, A., Ucbasaran, D., Zhu, F., \& Hirst, G. (2014). Psychological capital: A review and synthesis. Journal of Organizational Behavior, 35(Suppl 1), S120-S138.

Parker, S. K. (1998). Enhancing role breadth self-efficacy: The roles of job enrichment and other organizational interventions. The Journal of Applied Psychology, 83(6), 835-852.

Podsakoff, P. M., MacKenzie, S. B., Lee, J.-Y., \& Podsakoff, N. P. (2003). Common method biases in behavioral research: A critical review of the literature and recommended remedies. The Journal of Applied Psychology, 88(5), 879-903.

R: A language and environment for statistical computing (2019). R Core Team. R foundation for statistical computing, $1,409$.

Revelle, W. R. (2019). Psych: Procedures for psychological, psychometric, and personality research, $R$ package 1.8.4. Retrieved from https://CRAN.R-project.org/package=psych/ 
Rosseel, Y. (2012). Lavaan: An R Package for Structural Equation Modeling. Journal of Statistical Software, 48(2), 1-36. https://www.jstatsoft.org/v48/i02/.

Scheier, M. F., \& Carver, C. S. (1985). Optimism, coping, and health: Assessment and implications of generalized outcome expectancies. Health Psychology, 4(3), 219-247.

Seligman, M. E. P., \& Csikszentmihalyi, M. (2000). Positive psychology: An introduction. The American Psychologist, 55(1), 5-14.

Sin, N. L., \& Lyubomirsky, S. (2009). Enhancing well-being and alleviating depressive symptoms with positive psychology interventions: A practice-friendly meta-analysis. Journal of Clinical Psychology, 65(5), 467-487.

Spector, P. E. (2006). Overview of the Job-Related Affective Well-Being Scale (JAWS). Retrieved from http://shell.cas.usf.edu/ pspector/scales/jawsover.html

Snyder, C. R., Sympson, S. C., Ybasco, F. C., Borders, T. F., Babyak, M. A., \& Higgins, R. L. (1996). Development and validation of the state Hope scale. Journal of Personality and Social Psychology, $70(2), 321-335$.

Tavakol, M., \& Dennick, R. (2011). Making sense of Cronbach's alpha. International Journal of Medical Education, 2, 53-55.

Van Katwyk, P. T., Fox, S., Spector, P. E., \& Kelloway, E. K. (2000). Using the job-related affective wellbeing scale (JAWS) to investigate affective responses to work stressors. Journal of Occupational Health Psychology, 5, 219-230.

Warren, M. A., Donaldson, S. I., \& Luthans, F. (2017). Taking positive psychology to the workplace: Positive organizational psychology, positive organizational behavior, and positive organizational scholarship. In I. M. A. Warren \& S. I. Donaldson (Eds.), Scientific advances in positive psychology. CT: Praeger.

Uncu, Y., Bayram, N., \& Bilgel, N. (2007). Job related affective well-being among primary health care physicians. European Journal of Public Health, 17, 514-519.

Wagnild, G. M., \& Young, H. M. (1993). Development and psychometric evaluation of the resilience scale. Journal of Nursing Measurement, 1(2), 165-178.

Wilkerson, G. B., Boer, N. F., Smith, C. B., \& Heath, G. W. (2008). Health-related factors associated with the healthcare costs of office workers. Journal of Occupational and Environmental Medicine, 50, 593-601.

Publisher's Note Springer Nature remains neutral with regard to jurisdictional claims in published maps and institutional affiliations. 